\title{
Measurements of Naturally Occurring Radioactive Materials for some Granite Rocks samples in the Eastern Desert Egypt.
}

\author{
S. Harb , A. H. El-Kamel ${ }^{* *}$, A. I. Abd El-Mageed ${ }^{* *}$, A. Abbady ${ }^{*}$, and \\ Wafaa Rashed** \\ * Physics department, Faculty of Science, Qena 83523, South Valley University. \\ **Physics department, Faculty of Science, Assiut University. \\ ***Environmental Radioactivity Measurements Labrotary, Physics department, Faculty of science, South Valley \\ University, Qena, Egypt
}

\begin{abstract}
The distribution of natural radionuclide $\gamma$-ray activities and their respective annual effective dose rates, produced by ${ }^{238} \mathrm{U},{ }^{226} \mathrm{Ra},{ }^{228} \mathrm{Ra},{ }^{235} \mathrm{U},{ }^{232} \mathrm{Th}$ and ${ }^{40} \mathrm{~K}$ were determined for igneous rock samples collected along the road between Idfu and Marsa Alam in eastern desert of Egypt. This subject is important in environmental radiological protection, since igneous rocks are widely used as building material. The variation in concentration of radionuclides for thirty igneous rock samples was determined. A HPGe spectrometer was used for quantification of gamma emitting radionuclides in the samples. All igneous rocks contained radionuclides from the uranium and thorium series as well as ${ }^{40} \mathrm{~K}$.

${ }^{238} \mathrm{U}$ concentrations in samples ranged from $12.03 \pm 0.88$ to $19.34 \pm 1.41 \mathrm{~Bq} \cdot \mathrm{kg}^{-1},{ }^{235} \mathrm{U}$ from $1.16 \pm 0.11$ to $4.83 \pm 0.44, \mathrm{~Bq} \cdot \mathrm{kg}^{-1},{ }^{226} \mathrm{Ra}$ from $9.69 \pm 0.82$ to $18.97 \pm 1.33 \mathrm{~Bq} \cdot \mathrm{kg}^{-1},{ }^{228} \mathrm{Ra}$ ranged from $10.24 \pm 0.70$ to $17.35 \pm 1.29,{ }^{232} \mathrm{Th}$ range from $9.99 \pm 0.67$ to $17.65 \pm 1.23 \mathrm{~Bq} \cdot \mathrm{kg}^{-1}$ and ${ }^{40} \mathrm{~K}$ from $298.58 \pm 21.74$ to $955.78 \pm 69.58 \mathrm{~Bq} \cdot \mathrm{kg}^{-1}$.
\end{abstract}

Keywords: igneous rock, natural radionuclides; HPGe spectrometer; absorbed dose rates

\section{Introduction}

${ }^{238} \mathrm{U},{ }^{235} \mathrm{U}$, and ${ }^{332} \mathrm{Th}$ are the parents of the three natural decay series, called the uranium $(\mathrm{U})$ series, the actinium series and the thorium (Th) series, respectively. Each of these series consists of many daughter products generated through successive decay of parent radionuclides. In the three long-lived series, decay cascades produce radioactive daughter nuclides, ultimately resulting in the stable isotopes of ${ }^{208} \mathrm{~Pb},{ }^{207} \mathrm{~Pb}$ and ${ }^{206} \mathrm{~Pb}$. Natural uranium is a composite of the isotopes ${ }^{238} \mathrm{U}(99.28 \%),{ }^{234} \mathrm{U}(0.0057 \%)$, and ${ }^{235} \mathrm{U}(0.72 \%)$ While on a mass basis there is far more ${ }^{238} \mathrm{U}$ than ${ }^{235} \mathrm{U}$ in a natural sample, the activity ratio is approximately $21: 1$ [1]. The behavior and distribution of these decay series radionuclides in the environment are based on their biogeochemistry and half-life $\left(\mathrm{t}_{1 / 2}\right)$, and the nature of their surroundings.

Gamma radiation emitted from naturally occurring radioisotopes, such as the radionuclides from the ${ }^{232} \mathrm{Th}$ and ${ }^{238} \mathrm{U}$ series and their decay products (also called terrestrial background radiation) and ${ }^{40} \mathrm{~K}$, which exist at trace levels in all ground formations, represents the main external source of irradiation to the human body.

The activity concentrations of radionuclides were measured using a HPGe spectrometer. The radium equivalent, the external hazard index, the absorbed dose and the annual effective dose were assessed and compared with results of other studies and with the worldwide average value in the United Nations Scientific Committee on the Effects of Atomic Radiation report [2].

\subsection{Samples collection and preparation}

\section{Materials and methods}

A total of 30 igneous rock samples were collected randomly along the road between [Idfu, Marsa Alam] in eastern desert of Egypt figure 1. The masses of the collected samples varied between 250 and $350 \mathrm{gm}$. The samples were ground and crushed to fine grain size of about 100 mesh to small pieces and sieved in order to homogenize it and remove big size. The samples were then drying at $100 \mathrm{oC}$ for $48 \mathrm{~h}$ to ensure that moisture is completely removed. The powdered samples were packed in a standard plastic container $(7.5 \times 5.5 \mathrm{~cm})$ and after property tightening the threatened lid, the containers were sealed with adhesive tape and left for at least 4 weeks before counting by gamma spectrometry in order to ensure that the daughter products of $226 \mathrm{Ra}$ up to $210 \mathrm{~Pb}$ and of $232 \mathrm{Th}$ up to $208 \mathrm{~Pb}$ in secular equilibrium with their respective parent radionuclides and then the gamma ray spectrum was accumulated to up to $900 \mathrm{~min}$ [3]. 

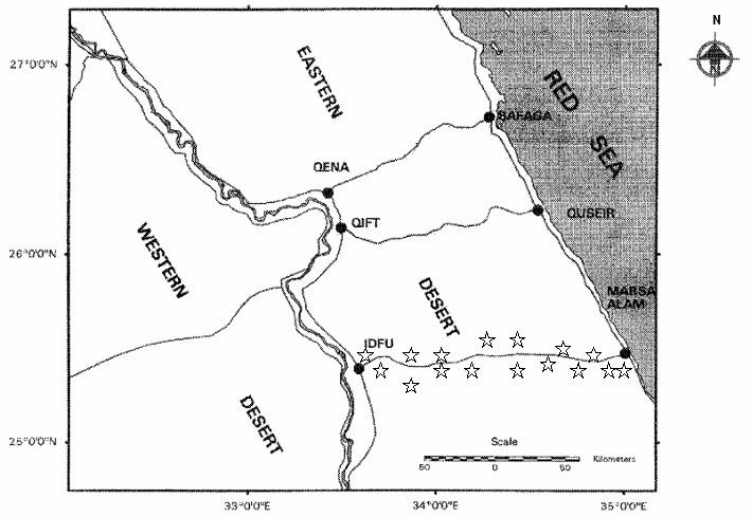

Fig. 1 map of samples sites (

\subsubsection{Sample counting and detector efficiency calibration}

The samples containers were placed into the active volume of a shielded high purity germanium (HPGe) detector with its electronic circuits and the lead shield contained two inner concentric cylinders of copper and cadmium. The detector has a potopeak relative efficiency of about $45 \%$ and an energy resolution of $1.91 \mathrm{keV}$ FWHM for the $1332 \mathrm{keV}$ gamma transition of ${ }^{60} \mathrm{Co}$. The detector was calibrated in absolute efficiency using a mixed twelve radionuclides gamma standard QCY48 [4], Table I (obtained from Physikalisch Technische Bundesanstalt PTB, Germany at 2006). The standard was enclosed in the same plastic container used for the measuring of igneous rock samples Figure 2.

The environmental $\gamma$-ray background at the laboratory site was determined using the same standard plastic container under identical measurement conditions from measurements prior, during and after the experiments, it was found that the background levels in the laboratory were maintained constant during the whole period of the measurements (one month).

Table I: Radionuclides used for efficiency calibration QCY48

\begin{tabular}{lllll}
\hline Nuclides & Energy $(\mathrm{keV})$ & Gamma rays/s & Uncertainty $(\%)$ & Half- life time $(\mathrm{d})$ \\
\hline Am-241 & 59.54 & 1128 & 2.6 & 158047 \\
Cd-109 & 88.03 & 647 & 6.2 & 462.6 \\
Co-57 & 122.1 & 588 & 1.5 & 271.4 \\
Ce-139 & 165.9 & 663 & 1.7 & 137.64 \\
Hg-203 & 279.2 & 1942 & 1.4 & 46.6 \\
Zn-113 & 391.7 & 2085 & 4.0 & 115.09 \\
Sr-85 & 514 & 3863 & 2.5 & 64.84 \\
Cs-137 & 661.6 & 2435 & 2.0 & 10958 \\
Y-88 & 898 & 6231 & 1.8 & 106.6 \\
Co-6 & 1173 & 3350 & 1.5 & 1924.9 \\
Co-61 & 1333 & 3353 & 1.5 & 1924.9 \\
Y-88 & 1836 & 6586 & 1.6 & 106.61 \\
\hline
\end{tabular}

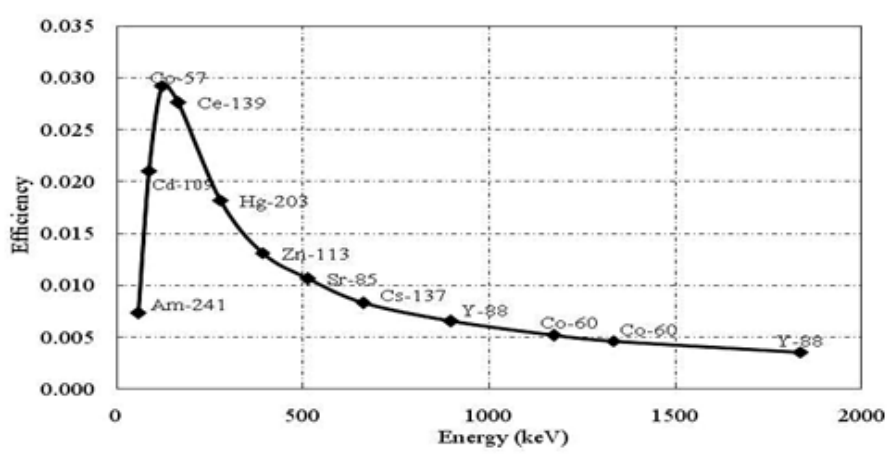

Fig.2. Full energy peak efficiency as a function of gamma ray energy for a typical HPGe detector

\subsubsection{Calculation of elemental concentration}

Count rates for each detected photopeak and activity for each of the detected nuclides are calculated. The specific activity (in Bq. $\mathrm{kg}^{-1}$ ), $\mathrm{A}_{E i}$ of a nuclide i. and for a peak at energy $\mathrm{E}$, is given by: 


$$
A_{E i}=\frac{N P}{t_{c} \times I_{\gamma}\left(E_{\gamma}\right) \times \varepsilon\left(E_{\gamma}\right) \times M}
$$

Where $N P$ is the number of count in a given peak area corrected for background peaks of a peak at energy $E$, $\varepsilon\left(E_{\gamma}\right)$ the detection efficiency at energy $E$, $\mathrm{t}$ is the counting time in second, $I_{\gamma}\left(E_{\gamma}\right)$ the number of gammas per disintegration of this nuclide for a transition at energy $E$, and $M$ is the mass in $\mathrm{kg}$ of the measured sample.

Under the assumption that secular equilibrium was reached between ${ }^{232} \mathrm{Th}$ and ${ }^{238} \mathrm{U}$ and their decay products, the $\gamma$-ray transitions to measure the concentration of the assigned nuclides in the series [4] are as follows:

(a) ${ }^{234 \mathrm{~m} m} \mathrm{~Pa}(1001.03 \mathrm{keV})$ for uranium-238.

(b) $\quad{ }^{214} \mathrm{Bi}(609.31,1120.3$ and $1764.49 \mathrm{keV}),{ }^{214} \mathrm{~Pb}(295.22$ and $351.93 \mathrm{keV})$ for radium-226.

(c) $\quad{ }^{208} \mathrm{Tl}(583.19$ and $2614.53 \mathrm{keV}),{ }^{212} \mathrm{~Pb}(238.63$ and $300.09 \mathrm{keV})$ and ${ }^{212} \mathrm{Bi}(727.3 \mathrm{keV})$ for the thorium series, as well as ${ }^{228} \mathrm{Ac}(338.32,463.1,911.20$ and $968.97 \mathrm{keV})$ for radium-228.

(d) ${ }^{40} \mathrm{~K}(1460.83 \mathrm{keV})$ for potassium.

(e) ${ }^{235} \mathrm{U}$ activity concentration was calculated from equation 2 .

${ }^{235} \mathrm{U}$ and ${ }^{226} \mathrm{Ra}$ emit gamma- rays of energy $185.7 \mathrm{keV}\left(I_{\gamma}=57.2 \%\right)$ and $186.2 \mathrm{keV}\left(I_{\gamma}=3.6 \%\right)$, respectively. The detector energy resolution is not sufficient to easily separate these peaks. Therefore, the concentration of ${ }^{235} \mathrm{U}$ was calculated by subtracting the fraction of ${ }^{226} \mathrm{Ra}$ using the following equation:

$$
{ }^{235} U=\frac{\left(\frac{\left(\frac{C R_{187}}{\varepsilon_{\text {Peak }}}\right)}{M}-\left[{ }^{226} R a\right] I_{\gamma}{ }^{226} R a\right)}{I_{\gamma}{ }^{235} U}
$$

where $C R_{187}$ is the count rate of the peak centered at $187 \mathrm{keV}, \varepsilon_{\text {Peak }}$ is the detector efficiency at that energy, $M$ is the mass of the sample (kg), $I_{\gamma}{ }^{226} R a$ is the gamma-ray emission fraction for ${ }^{226} \mathrm{Ra}, I_{\gamma}{ }^{235} U$ is the gammaray emission fraction for $\left.{ }^{235} \mathrm{U},{ }^{226} \mathrm{Ra}\right]$ is the activity concentration of ${ }^{226} \mathrm{Ra}$ in the sediment $\left(\mathrm{Bq} \cdot \mathrm{kg}^{-1}\right)$ based on the average of the ${ }^{214} \mathrm{Bi}$ and ${ }^{214} \mathrm{~Pb}$ analyses, and $\left[{ }^{235} \mathrm{U}\right.$ is the concentration of ${ }^{235} \mathrm{U}$ in the sediment $\left(\mathrm{Bq} \cdot \mathrm{kg}^{-1}\right)$ [1]. The analysis of output spectrum was carried out with the help of commercial software programme Maestro 2.1 (EG\&G ORTIC), and manually with the use of a spread sheet (Microsoft Excel).

\subsubsection{Calculation of Statistical error for measurement process}

To correct $A_{E i}$ to actual activity in sample, we must apply the necessary corrections to the count rate. Some typical corrections include:

1. Counter efficiency $=\varepsilon$

2. emission probability of emitted radiation $=I$

We can get the relative uncertainties of input value.

\section{Where}

$$
\frac{\mathbf{u}^{2}\left(\mathbf{A}_{\mathrm{s}}\right)}{\mathbf{A}_{\mathrm{s}}^{2}}=\frac{\mathbf{u}^{2}(\mathrm{NP})}{(\mathbf{N P})^{2}}+\frac{\mathbf{u}^{2}\left(\mathbf{t}_{\mathrm{C}}\right)}{\left(\mathbf{t}_{\mathrm{C}}^{2}\right)}+\frac{\mathbf{u}^{2} \boldsymbol{I}_{\gamma}\left(\mathbf{E}_{\gamma}\right)}{\boldsymbol{I}_{\gamma}^{2}\left(\mathbf{E}_{\gamma}\right)}+\frac{\mathbf{u}^{2} \varepsilon\left(\mathbf{E}_{\gamma}\right)}{\varepsilon^{2}\left(\mathbf{E}_{\gamma}\right)}+\frac{\mathbf{u}^{2}(\mathbf{M})}{\left(\mathbf{M}^{2}\right)}
$$

$$
\begin{aligned}
& \frac{u(N P)}{(N P)} \text { from spectra evaluation } \\
& N P \quad=N P-N_{0}
\end{aligned}
$$

where the $N P$ is net peak and $\mathrm{N}_{0}$ is counting of background

\subsubsection{Radium equivalent activity $\left(\mathbf{R a}_{\mathrm{eq}}\right)$}

\section{Calculation of radiological effects}

Distribution of ${ }^{226} \mathrm{Ra},{ }^{232} \mathrm{Th}$ and ${ }^{40} \mathrm{~K}$ in environment is not uniform, so that with respect to exposure to radiation, the radioactivity has been defined in terms of radium equivalent activity $\left(R a_{e q}\right)$ in $\mathrm{Bq} \cdot \mathrm{kg}^{-1}$ to compare the specific activity of materials containing different amounts of ${ }^{226} \mathrm{Ra},{ }^{232} \mathrm{Th}$ and ${ }^{40} \mathrm{~K}[5]$.

$$
R a_{e q}=C_{R a}+1.43 C_{T h}+0.077 C_{K}
$$

Where $C_{R a}, C_{T h}$ and $C_{K}$ are specific activity concentration in Bk.kg ${ }^{-1}$ of ${ }^{226} \mathrm{Ra},{ }^{232} \mathrm{Th}$ and ${ }^{40} \mathrm{~K}$,

respectively. The index is useful to compare the specific activity of materials containing different concentrations of ${ }^{226} \mathrm{Ra},{ }^{232} \mathrm{Th}$ and ${ }^{40} \mathrm{~K}$. 


\subsubsection{Estimation of gamma radiation doss $(\mathrm{D})$ :}

UNSCEAR [2] has given the dose conversion factors for converting the activity concentrations of ${ }^{238} \mathrm{U}$, ${ }^{232} \mathrm{Th}$ and ${ }^{40} \mathrm{~K}$ into doses $\left(\mathrm{nGy} \cdot \mathrm{h}^{-1}\right.$ per Bq.kg ${ }^{-1}$ ) as $0.427,0.662$ and 0.043 , respectively.

The gamma radiation population doses of those living $\mathrm{m}$ the area are given as:

$$
D=0.427 C_{U}+0.662 C_{T h}+0.043 C_{K}
$$

Where $\mathrm{D}$ is the dose rate in nGy.h ${ }^{-1}$ and $C_{U}, C_{T h}$ and $C_{K}$ are the concentrations of uranium, thorium and potassium, respectively.

\subsubsection{Representative level index $\left(I_{\gamma r}\right)$ :}

In order to examine whether the samples meets these limits of dose criteria, Another radiation hazard index, the representative level index, $I_{y r}$, used to estimate the level of $\gamma$-radiation hazard associated with the natural radionuclides in specific investigated samples, is defined as [6] from the following Equation (6):

$$
I_{\gamma r}=\frac{A_{R a}}{150}+\frac{A_{T h}}{100}+\frac{A_{K}}{1500}
$$

Where $A_{R a}, A_{T h}$ and $A_{K}$ are the concentrations of ${ }^{226} \mathrm{Ra},{ }^{232} \mathrm{Th}$ and ${ }^{40} \mathrm{~K}$, respectively, in Bq.kg .

\subsubsection{External hazard index $\left(\mathrm{H}_{\mathrm{ex}}\right)$ :}

The ultimate use of the measured activities in building materials is to estimate the radiation dose expected to be delivered externally if a building is constructed using these materials. To limit the annual external gamma-ray dose to $1.5 \mathrm{mSv} \cdot \mathrm{y}^{-1}$ (Saito et al., 1998; (UNSCEAR, 2000), the external hazard index $\left(H_{e x}\right)$ is given by the following equation:

$$
H_{e x}=\frac{A_{R a}}{370}+\frac{A_{T h}}{259}+\frac{A_{K}}{4810}
$$

1.1.8. Internal hazard index $\left(\mathbf{H}_{\text {in }}\right)$ :

The internal exposure $t{ }^{222} \mathrm{Rn}$ and its radioactive progeny is controlled by the interned hazard index $\left(H_{\text {in }}\right)$ which is given by $[7,8]$.

$$
H_{\text {in }}=\frac{A_{R a}}{185}+\frac{A_{T h}}{259}+\frac{A_{K}}{4810} ;
$$

For the safe use of a material in the construction of dwellings, index $\left(H_{\text {in }}\right)$ should be less than unity and the maximum value of $\left(H_{i n}\right)$ to be less than unity [9].

\section{Results and discussion}

As can be seen from Table 2 the activities of the ${ }^{235} \mathrm{U},{ }^{238} \mathrm{U},{ }^{226} \mathrm{Ra},{ }^{228} \mathrm{Ra},{ }^{232} \mathrm{Th}$, and ${ }^{40} \mathrm{~K}$ activities, calculated with the individual activity estimates and weighted by the reciprocal of their variances. The indicated ${ }^{226} \mathrm{Ra}$ value corresponds to the mean calculated with the two ${ }^{214} \mathrm{~Pb}$ and the three ${ }^{214} \mathrm{Bi}$ full absorption peaks.

The concentration of ${ }^{235} \mathrm{U},{ }^{238} \mathrm{U}$ and ${ }^{226} \mathrm{Ra}$ varied from $1.16 \pm 0.11$ to $4.83 \pm 0.44$, from $12.03 \pm 0.88$ to $19.34 \pm 1.41$ and from $9.69 \pm 0.82$ to $18.97 \pm 1.33$ with average values $2.23 \pm 0.21,15.64 \pm 1.14$ and $13.72 \pm 1.01 \mathrm{~Bq} \cdot \mathrm{kg}^{-1}$, respectively.

Also Table 2 presents the activity concentration of ${ }^{228} \mathrm{Ra},{ }^{232} \mathrm{Th}$, and ${ }^{40} \mathrm{~K}$ ranged from $10.24 \pm 0.70$ to $17.35 \pm 1.29$, from $9.99 \pm 0.67$ to $17.65 \pm 1.23$ and from $298.58 \pm 21.74$ to $955.78 \pm 69.58$ with average values $14.12 \pm 1.06,14.46 \pm 1.08$ and $405.73 \pm 29.54 \mathrm{Bqkg}^{-1}$, respectively. All the measured samples have ${ }^{238} \mathrm{U}$ and ${ }^{232} \mathrm{Th}$ concentrations less than the average value of $35 \mathrm{Bqkg}^{-1}$ from the UNSCEAR survey. The ${ }^{238} \mathrm{U} /{ }^{226} \mathrm{Ra}$ and the ${ }^{232} \mathrm{Th} /{ }^{228} \mathrm{Ra}$ activity ratio ranged from 0.83 to 1.60 with an average value of 1.17 , and from 0.88 to 1.17 with an average value of 1.03 , respectively, which closed to the unity. 
Table.2: The activities concentrations of the ${ }^{235} \mathrm{U},{ }^{238} \mathrm{U},{ }^{226} \mathrm{Ra},{ }^{228} \mathrm{Ra},{ }^{232} \mathrm{Th}$, and ${ }^{40} \mathrm{~K}$ in $\mathrm{Bq} \cdot \mathrm{kg}^{-1}$ for the measured samples.

\begin{tabular}{|c|c|c|c|c|c|c|c|c|}
\hline $\begin{array}{c}\text { Samples } \\
\text { No. }\end{array}$ & ${ }^{235} \mathrm{U}$ & ${ }^{238} \mathbf{U}$ & ${ }^{226} \mathbf{R a}$ & ${ }^{228} \mathbf{R a}$ & ${ }^{232} \mathrm{Th}$ & ${ }^{40} K$ & ${ }^{238} \mathrm{U}^{226} \mathbf{R a}$ & ${ }^{232} \mathrm{Th} /{ }^{228} \mathrm{Ra}$ \\
\hline 2 & $2.0 \pm 0.2$ & $13.1 \pm 0.9$ & $13.1 \pm 1.0$ & $14.2 \pm 0.9$ & $13.1 \pm 0.9$ & $378 \pm 28$ & 1.00 & 0.93 \\
\hline 4 & $1.9 \pm 0.2$ & $17.9 \pm 1.3$ & $12.4 \pm 0.9$ & $12.5 \pm 0.8$ & $13.6 \pm 1.0$ & $352 \pm 26$ & 1.44 & 1.09 \\
\hline 5 & $2.4 \pm 0.2$ & $17.7 \pm 1.3$ & $15.5 \pm 1.2$ & $16.6 \pm 1.5$ & $15.0 \pm 1.1$ & $403 \pm 29$ & 1.14 & 0.91 \\
\hline 6 & $1.4 \pm 0.1$ & $16.3 \pm 1.2$ & $12.5 \pm 0.9$ & $16.1 \pm 1.1$ & $16.9 \pm 1.5$ & $403 \pm 29$ & 1.31 & 1.06 \\
\hline 9 & $1.2 \pm 0.1$ & $12.6 \pm 0.9$ & $12.1 \pm 0.9$ & $10.6 \pm 0.9$ & $10.1 \pm 0.7$ & $357 \pm 26$ & 1.04 & 0.95 \\
\hline 10 & $2.2 \pm 0.2$ & $17.6 \pm 1.3$ & $11.7 \pm 0.9$ & $12.0 \pm 1.2$ & $13.3 \pm 1.1$ & $362 \pm 26$ & 1.50 & 1.11 \\
\hline 11 & $2.3 \pm 0.2$ & $14.3 \pm 1.0$ & $14.7 \pm 1.1$ & $13.7 \pm 0.9$ & $14.8 \pm 1.1$ & $365 \pm 27$ & 0.97 & 1.08 \\
\hline 12 & $2.2 \pm 0.2$ & $17.7 \pm 1.3$ & $15.1 \pm 1.1$ & $17.4 \pm 1.3$ & $16.8 \pm 1.3$ & $361 \pm 26$ & 1.17 & 0.97 \\
\hline 13 & $1.2 \pm 0.1$ & $13.1 \pm 0.9$ & $11.6 \pm 0.9$ & $11.9 \pm 0.8$ & $13.4 \pm 0.9$ & $327 \pm 24$ & 1.13 & 1.12 \\
\hline 18 & $2.0 \pm 0.2$ & $16.2 \pm 1.2$ & $11.1 \pm 0.9$ & $14.5 \pm 1.0$ & $15.6 \pm 1.2$ & $387 \pm 28$ & 1.45 & 1.08 \\
\hline 19 & $1.9 \pm 0.2$ & $12.0 \pm 0.9$ & $9.7 \pm 0.8$ & $12.0 \pm 0.9$ & $12.1 \pm 0.9$ & $349 \pm 25$ & 1.24 & 1.01 \\
\hline 20 & $2.4 \pm 0.2$ & $13.8 \pm 1.0$ & $13.9 \pm 1.1$ & $14.9 \pm 1.2$ & $13.7 \pm 0.9$ & $376 \pm 27$ & 0.99 & 0.92 \\
\hline 21 & $2.3 \pm 0.2$ & $15.3 \pm 1.1$ & $12.7 \pm 0.9$ & $13.7 \pm 1.1$ & $15.2 \pm 1.1$ & $395 \pm 29$ & 1.20 & 1.11 \\
\hline 22 & $2.7 \pm 0.3$ & $19.3 \pm 1.4$ & $17.6 \pm 1.2$ & $16.3 \pm 1.4$ & $16.2 \pm 1.2$ & $442 \pm 32$ & 1.10 & 1.00 \\
\hline 23 & $2.2 \pm 0.2$ & $18.1 \pm 1.3$ & $13.9 \pm 0.9$ & $13.2 \pm 0.9$ & $13.6 \pm 1.0$ & $383 \pm 28$ & 1.30 & 1.03 \\
\hline 24 & $2.1 \pm 0.2$ & $15.7 \pm 1.1$ & $14.9 \pm 1.0$ & $15.3 \pm 1.1$ & $13.5 \pm 0.9$ & $304 \pm 22$ & 1.04 & 0.88 \\
\hline 25 & $2.4 \pm 0.2$ & $17.6 \pm 1.3$ & $14.2 \pm 1.1$ & $14.8 \pm 1.1$ & $15.7 \pm 1.1$ & $398 \pm 29$ & 1.24 & 1.06 \\
\hline 26 & $2.4 \pm 0.2$ & $13.4 \pm 0.9$ & $11.8 \pm 0.9$ & $10.3 \pm 0.8$ & $9.9 \pm 0.7$ & $299 \pm 22$ & 1.13 & 0.97 \\
\hline 27 & $4.2 \pm 0.4$ & $18.8 \pm 1.4$ & $11.7 \pm 0.8$ & $15.3 \pm 0.7$ & $15.7 \pm 1.3$ & $488 \pm 36$ & 1.60 & 1.03 \\
\hline 28 & $4.8 \pm 0.4$ & $19.3 \pm 1.4$ & $17.0 \pm 1.4$ & $14.6 \pm 1.3$ & $15.9 \pm 1.1$ & $956 \pm 70$ & 1.14 & 1.09 \\
\hline
\end{tabular}

Table 3 compares the reported values of natural radioactivity for igneous rock obtained in other published data with those determined in this study. As shown in table 3, the radioactivity in igneous rock samples varied from one country to another. It is important to point out that these values were not the representative values for the countries mentioned but for the regions from where the samples were collected. The values of the radionuclides concentration for all the selected igneous rock samples in present study were closed to be in the same range may be low of the corresponding material in other published.

It is important to assess the gamma radiation hazards to human associated with the used these samples for buildings; these were done by calculating the different radiation hazard indices. The radium equivalent activities of samples under investigation were calculated on the basis of equation (4) and are shown in Table 4. The average $R a_{e q}$ value for the studied area $65.51 \mathrm{~Bq} \cdot \mathrm{kg}^{-1}$ are below the internationally accepted value 370 Bq. $\mathrm{kg}^{-1}$.

Table 3 Comparison of radionuclides concentrations $\left(\mathrm{Bq} \mathrm{kg}^{-1}\right)$ in igneous rock samples with those obtained in other published data

\begin{tabular}{|l|l|l|l|c|}
\hline \multicolumn{1}{|c|}{ Country } & \multicolumn{1}{c|}{${ }^{226} \mathrm{Ra}$} & \multicolumn{1}{c|}{${ }^{232} \mathrm{Kh}$} & Reference \\
\hline $\begin{array}{l}\text { Egypt (eastern desert road } \\
\text { of Idfu and Marsa Alam) }\end{array}$ & $\begin{array}{l}9.69-18.97 \\
(13.72)\end{array}$ & $\begin{array}{l}9.99-17.65 \\
(14.46)\end{array}$ & $\begin{array}{l}298.58-955.78 \\
(405.73)\end{array}$ & Present work. \\
\hline Egypt (eastern desert) & 30 & 63 & 1335.2 & {$[10]$} \\
\hline Egypt (Um Taghir) & $2.9-9087$ & $1.4-3834$ & $132-10230$ & {$[11]$} \\
\hline Egypt (W.Allaki) & $10-90$ & $98-160$ & $73-102$ & {$[12]$} \\
\hline Egypt (W.Um Had) & $102-640$ & $56-161$ & $774-1234$ & {$[13]$} \\
\hline Egypt (Gabel El Majal) & $35.5-505.5$ & $11-72.2$ & $203-1573$ & {$[14]$} \\
\hline Egypt (El Aradiya) & $5.3-336.7$ & $3.1-64.4$ & $160-774$ & {$[14]$} \\
\hline Brazil (Commercial granite) & $5.2-169$ & $4.5-448.5$ & $190-2028$ & {$[15]$} \\
\hline China (Commercial granite) & $14.5-204.7$ & $16.7-186.7$ & $185.7-1745.6$ & {$[16]$} \\
\hline Cyprus & $1-588$ & $1-906$ & $50-1606$ & {$[17]$} \\
\hline Greece & $1.6-170$ & $30-354$ & $49-1592$ & {$[18]$} \\
\hline Kenya & 23.1 & 24.7 & 931.3 & {$[19]$} \\
\hline Turkey & $43-651$ & $51-351$ & $418-1618$ & {$[20]$} \\
\hline
\end{tabular}


Along the road between Idfu and Marsa Alam in eastern desert of Egypt, the absorbed dose rate fluctuated from 24.24 to $58.05 \mathrm{nGy} \cdot \mathrm{h}^{-1}$, with a mean value of $32.50 \mathrm{nGy} \cdot \mathrm{h}^{-1}$. These calculated values were lower than the estimate of average global terrestrial radiation of $55 \mathrm{nGy} \cdot \mathrm{h}^{-1}$ except sample No. 28 because of the uranium concentration in the sampling region is more dependent upon the climate, seasonal variability and the effects of evapotranspiration and the concentration of suitable complexing agents which can increase the solubility of uranium. The concentrations vary considerably spatially and temporally. The temporal variation may be seasonal, affecting changes in rainfall and run-off. Increased rainfall may result in more effective leaching and/or transport of uranium and lead to an increase in uranium concentration, consequently increasing of radiological effects.

The value of radiation hazard index called the representative level index $I_{\gamma r}$ equation (6) must be less than unity for the radiation hazard to be negligible, i.e. the average value of level index for the studied samples in this work ranging from 0.53 to 1.14 . The $I_{y r}$ values are below the internationally accepted value 1 except in one sample.

The calculated external gamma-ray dose have an average values less than the acceptable value $1.5 \mathrm{mSv}^{-1} \mathrm{y}^{-1}[21$, 22], as shown in Table 4.

The external hazard index $\left(H_{e x}\right)$ and internal hazard index $\left(H_{i n}\right)$, values for the studied areas are below the internationally accepted values. For the safe use of a material in the construction of dwellings, index $\left(H_{\text {in }}\right)$ should be less than unity (from 0.13 to 0.31$)$. For the maximum value of $\left(H_{\text {in }}\right)$ to be less than unity [9]. The average calculated values of $\left(H_{\text {in }}\right)$ for the samples studied in the investigated area ranging from 0.16 to 0.35 as shown in Table 3. Therefore, the use of these materials in construction of dwellings is considered to be safe for inhabitants.

Table.4: The calculated values of External hazard index $\left(H_{e x}\right)$, Internal hazard index $\left(H_{i n}\right)$, level index $I_{\gamma r}$, dose rate and radium equivalent $R a_{e q}$ of the samples under investigation.

\begin{tabular}{|c|c|c|c|c|c|}
\hline Sample & $R a_{e q}$ & $D$ & $I_{\gamma r}$ & $H_{\text {in }}$ & $H_{e x}$ \\
\hline 1 & 61.12 & 30.10 & 0.64 & 0.17 & 0.20 \\
\hline 2 & 60.99 & 30.25 & 0.65 & 0.16 & 0.20 \\
\hline 3 & 60.69 & 30.08 & 0.64 & 0.16 & 0.20 \\
\hline 4 & 58.94 & 29.16 & 0.62 & 0.16 & 0.19 \\
\hline 5 & 67.90 & 33.53 & 0.73 & 0.18 & 0.23 \\
\hline 6 & 67.78 & 33.58 & 0.69 & 0.18 & 0.22 \\
\hline 7 & 66.68 & 32.76 & 0.69 & 0.18 & 0.22 \\
\hline 8 & 62.35 & 30.68 & 0.66 & 0.17 & 0.21 \\
\hline 9 & 53.99 & 26.89 & 0.58 & 0.15 & 0.18 \\
\hline 10 & 58.67 & 29.12 & 0.61 & 0.16 & 0.19 \\
\hline 11 & 63.95 & 31.49 & 0.69 & 0.17 & 0.21 \\
\hline 12 & 66.83 & 32.79 & 0.71 & 0.18 & 0.22 \\
\hline 13 & 55.93 & 27.63 & 0.58 & 0.15 & 0.18 \\
\hline 14 & 67.45 & 33.31 & 0.70 & 0.18 & 0.22 \\
\hline 15 & 70.78 & 34.75 & 0.77 & 0.19 & 0.24 \\
\hline 16 & 63.70 & 31.52 & 0.65 & 0.17 & 0.20 \\
\hline 17 & 52.28 & 26.14 & 0.55 & 0.14 & 0.17 \\
\hline 18 & 63.30 & 31.45 & 0.64 & 0.17 & 0.20 \\
\hline 19 & 53.88 & 26.88 & 0.55 & 0.15 & 0.17 \\
\hline 20 & 62.52 & 30.91 & 0.67 & 0.17 & 0.21 \\
\hline 21 & 64.91 & 32.19 & 0.67 & 0.18 & 0.21 \\
\hline 22 & 74.86 & 36.93 & 0.81 & 0.20 & 0.25 \\
\hline 23 & 62.86 & 31.11 & 0.67 & 0.17 & 0.21 \\
\hline 24 & 57.69 & 28.19 & 0.64 & 0.16 & 0.20 \\
\hline 25 & 67.31 & 33.27 & 0.71 & 0.18 & 0.22 \\
\hline 26 & 49.05 & 24.24 & 0.53 & 0.13 & 0.16 \\
\hline 27 & 71.76 & 35.99 & 0.72 & 0.19 & 0.23 \\
\hline 28 & 113.39 & 58.05 & 1.14 & 0.31 & 0.35 \\
\hline 29 & 55.49 & 27.17 & 0.60 & 0.15 & 0.19 \\
\hline 30 & 108.20 & 54.89 & 1.11 & 0.29 & 0.34 \\
\hline Min. & 49.05 & 24.24 & 0.53 & 0.13 & 0.16 \\
\hline Max. & 113.39 & 58.05 & 1.14 & 0.31 & 0.35 \\
\hline Mean Value & 65.51 & 32.50 & 0.69 & 0.18 & 0.21 \\
\hline
\end{tabular}

\section{Conclusions}

The variation in concentration of radionuclides for thirty igneous rock samples was determined. The activity concentrations of ${ }^{226} \mathrm{Ra},{ }^{214} \mathrm{Bi},{ }^{214} \mathrm{~Pb}$ (from ${ }^{238} \mathrm{U}$ decay series), ${ }^{228} \mathrm{Ac},{ }^{212} \mathrm{Bi},{ }^{212} \mathrm{~Pb}$ (from ${ }^{232} \mathrm{Th}$ decay series) .and ${ }^{40} \mathrm{~K}$ were measured using a HPGe spectrometer. The mean value activity concentration of ${ }^{238} \mathrm{U}$ in samples was $\left(15.64 \pm 1.14 \mathrm{~Bq} \cdot \mathrm{kg}^{-1}\right),{ }^{235} \mathrm{U}\left(2.23 \pm 0.21 \mathrm{~Bq} \cdot \mathrm{kg}^{-1}\right),{ }^{226} \mathrm{Ra}\left(13.72 \pm 1.01 \mathrm{~Bq} \cdot \mathrm{kg}^{-1}\right),{ }^{228} \mathrm{Ra}(14.12 \pm 1.06),{ }^{232} \mathrm{Th}(14.46 \pm 1.08$ $\left.\mathrm{Bq} \cdot \mathrm{kg}^{-1}\right)$ and ${ }^{40} \mathrm{~K}\left(405.73 \pm 29.54 \mathrm{~Bq} \cdot \mathrm{kg}^{-1}\right)$. The results can be considered as base values for distribution of natural radionuclides in the region and will be used as reference information to assess any changes in the radioactive background level due to geological processes. 


\section{References}

[1] B. A. Powell, Lara D. Hughes, Aurelie M. Soreefan, Deborah Falta, Michael Wall, Timothy A. DeVol,. Journal of Environmental Radioactivity 94, (2007),121-128.

[2] UNSCEAR,. United Nations Scientific Committee on the Effects of Atomic Radiation, United Nations, New York (1988).

[3] S. Isam, M. M., H. B. L.Pettersson, and E. Lund, Radiation Protection Dosimetry, 102(3), (2002), 249-258.

[4] S. Harb, Ph.D. Thesis, Center for radation protection and radioecology (ZSR), Hannover University, Germany, (2004).

[5] I. Beretka, P.I. Mathew, Health Physics 48, (1985), 87-95.

[6] NEA-OECD,. Report by NEA Group of Experts. OECD, Paris, (1979).

[7] L. S.Quindos, P. L. Fernandez, J. Soto, Building materials as source of exposure in houses. In: Seifert, B., Esdorn, H. (Eds.), Indoor Air, 87, vol. 2. Institute for Water, Soil and Air Hygiene, Berlin, p. 365, 1987.

[8] E. Cottens, Actions against radon at the international level. In: Proceedings of the Symposium on SRBII, Journee Radon, Royal Society of Engineers and Industrials of Belgium, Brussels, 17 January (1990).

[9] M.Iqbal, M.Tufail, M.Mirza, Journal of Environmental Radioactivity 51, (2000), 255-265.

[10] N. Walley El- Dine, A. El-Shershaby, F. Ahmed, and A. S. Abdel-Haleem, Applied Radiation and Isotopes, 55, (2001), 853-860.

[11] A. M. El-Arabi, N. K.Ahmed, , A. H.El-Kamel, Arab J. Nucl. Sci. Appl. 34 (part II), (2001), 245-255

[12] A. M. El-Arabi, Indian Journal Pure Applied Physics 43, (2005). 422-426.

[13] A. M. El-Arabi,. Radiation Measurements 42, (2007), 94-100.

[14] W. Arafa, Journal of Environmental Radioactivity 75, (2004), 315-327.

[15] R. Anjos, R. Veiga, T. Soares, A.Santos, J. Aguiar, M.Frascac, J.Brage, D. Uzêda, L. Mangia, A. Facure, B. Mosquera, C. Carvalho, P.Gomes, Radiation Measurements 39, (2005) 245-253.

[16] L. Xinwei, W. Lingqing, J. Xiaodan, , Y. Leipeng, and D. Gelian, Radiation Protection Dosimetry, 118 (3), (2006) $352-359$.

[17] M. Tzortzis, H. Tsertos, S. Christofides, and G.Christodoulides, Journal of Environmental Radioactivity, 70, (2003) $223-235$.

[18] C. Papastefanou, S. Stoulos, and Manolopoulou. Journal of Radioanalytical and Nuclear Chemistry, 266 (3), (2005), $367-372$.

[19] A. O. Mustapha, D. G. S. Narayana, J. P. Patel, and D.Otwoma, Radiation Protection Dosimetry, 71 (1), (1997), 65-69.

[20] Y. Orgun, N. Altınsoy, A. H. Gultekin, G. Karahan, and N. Celebi, Appllied Radiaiont and Isotopes, 63, (2005), 267-275.

[21] K. Saito, H.Petoussi, M. Zanki, Health Physics, 74, (1998), 698-706.

[22] UNSCEAR, United Nations Scientific Committee on the Effects of Atomic Radiation, United Nations, New York, (2000). 